\title{
APT Blanket Thermal Analyses of Top Horizontal Row 1 Modules
}

\author{
M. A. Shadday and L. L. Hamm \\ Westinghouse Savannah River Company \\ Aiken, SC 29808
}

This document was prepared in conjunction with work accomplished under Contract No. DE-AC09-96SR18500 with the U.S. Department of Energy.

DISCLAIMER

\begin{abstract}
This report was prepared as an account of work sponsored by an agency of the United States Government. Neither the United States Government nor any agency thereof, nor any of their employees, makes any warranty, express or implied, or assumes any legal liability or responsibility for the accuracy, completeness, or usefulness of any information, apparatus, product or process disclosed, or represents that its use would not infringe privately owned rights. Reference herein to any specific commercial product, process or service by trade name, trademark, manufacturer, or otherwise does not necessarily constitute or imply its endorsement, recommendation, or favoring by the United States Government or any agency thereof. The views and opinions of authors expressed herein do not necessarily state or reflect those of the United States Government or any agency thereof.
\end{abstract}

This report has been reproduced directly from the best available copy.

Available to DOE and DOE Contractors from the Office of Scientific and Technical Information, P. O. Box 62, Oak Ridge, TN 37831; prices available from (423) 5768401.

Available to the public from the National Technical Information Service, U.S. Department of Commerce, 5285 Port Royal Road, Springfield, VA 22161.

\section{Introduction}

The Accelerator Production of Tritium (APT) cavity flood system (CFS) is designed to be the primary safeguard for the integrity of the blanket modules during loss of coolant accidents (LOCAs). For certain large break LOCAs the CFS also provides backup for the residual heat removal systems (RHRs) in cooling the target assemblies. In the unlikely event that the internal flow passages in a blanket module or target assembly dryout, decay heat in the metal structures will be dissipated to the CFS through the module or assembly walls (i.e., rung outer walls). The target assemblies consist of tungsten targets encased in steel conduits, and they can safely sustain high metal temperatures. Under internally dry conditions, the cavity flood fluid will cool the target assemblies with vigorous nucleate boiling on the external surfaces. However, the metal structures in the blanket modules consist of lead cladded in aluminum, and they have a long-term exposure temperature limit currently set to $150^{\circ} \mathrm{C}$.

Simultaneous LOCAs in both the target and blanket heat removal systems (HRS) could result in dryout of the target ladders, as well as the horizontal blanket modules above the target. The cavity flood coolant would boil on the outside surfaces of the target ladder rungs, and the resultant steam could reduce the effectiveness of convection heat transfer from the blanket modules to the cavity flood coolant. A two-part analysis was conducted to ascertain if the cavity flood system can adequately cool the blanket modules above the targets, even when boiling is occurring on the outer surfaces of the target ladder rungs. The first part of the analysis was to model transient thermal conduction in the front top horizontal row 1 module (i.e. top horizontal modules nearest the incoming beam), while varying parametrically the convection heat transfer coefficient (htc) for the external surfaces exposed to the cavity flood flow. This part of the analysis 
demonstrated that the module could adequately conduct heat to the outer module surfaces, given reasonable values for the convection heat transfer coefficients. The second part of the analysis consisted of two-phase flow modeling of the natural circulation of the cavity flood fluid past the top modules. Slots in the top shield allow the cavity flood fluid to circulate. The required width for these slots, to prevent steam from backing up and blanketing the outer surfaces of the top modules, was determined.

\section{Problem Description}

The cavity flood system protects the integrity of the target and blanket in the event of an accident that leaves either system partially or wholly internally dry. The target and blanket HRS are independent, and in general under LOCA conditions, the dryout status of the target HRS will not adversely influence the capacity of the cavity flood system to adequately cool the blanket modules. Heating and boiling of the cavity flood fluid by internally dry target ladder rungs will promote more vigorous natural circulation within the cavity vessel, and this will enhance natural convection cooling of the blanket modules. However, for the top blanket modules vigorous boiling of the cavity flood fluid by the target assemblies has the potential to interfere with their cooling. As shown in Figure 1, these modules are directly above the target ladders, and natural circulation of the cavity flood fluid would flow past these modules subsequent to flowing over the target ladder assemblies. If the target assemblies are internally dry, then the majority of decay heat must be dissipated to the surrounding cavity flood fluid. This results in boiling on the outer surfaces of each target rung, and a saturated two-phase mixture will flow past the top blanket modules. In the unlikely event that the blanket system has also lost its liquid inventory and depending upon the two-phase flow regime present, the steam could prevent adequate cavity flood cooling of the internally dry top blanket modules.

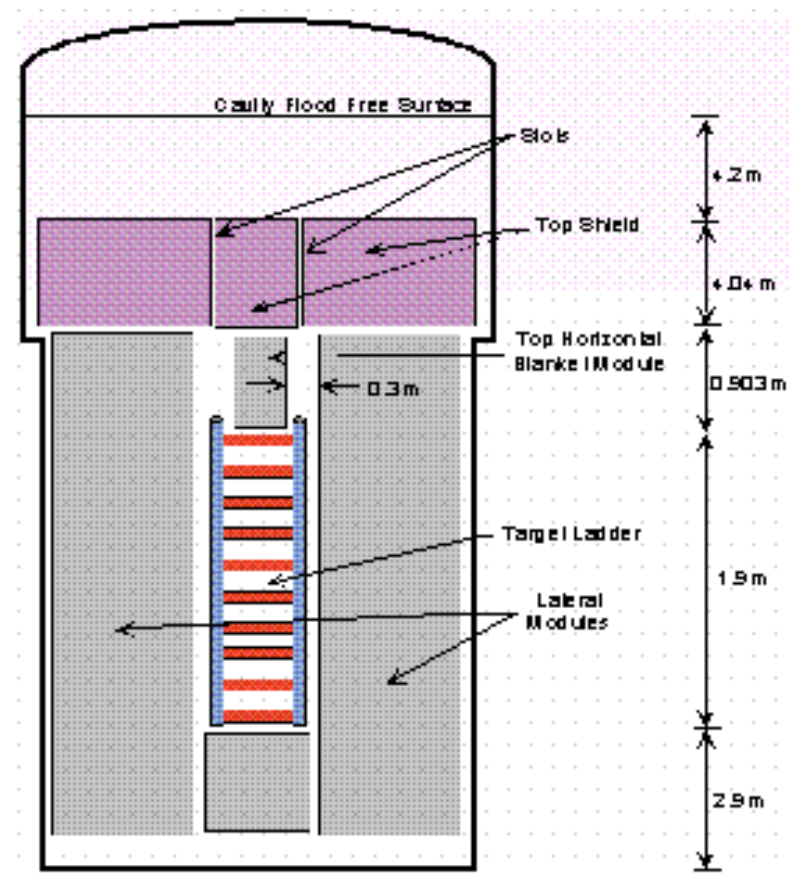

Figure 1. Schematic of the target vessel showing components to be cooled by the cavity flood system. 
There are two sets of horizontal top blanket modules (i.e., front and back sets) that are positioned above the target ladders and are oriented parallel to the accelerator beam. Figure 2 is a schematic of one of the row 1 top horizontal modules. It shows a vertical cross-section in a plane normal to the accelerator beam. The interior flow channels extend horizontally the entire axial length of the module. There are four parallel lead plates that extend the entire length of the module in the beamwise direction. The plates are separated by the helium tubes and flow channels, and they are clad with aluminum. There is a decoupler below the module and a row 2 module above it. The two sides of the module are exposed to the cavity flood fluid when this system is activated, and decay heat is transferred to the cavity flood fluid through these surfaces when there is no flow through the internal flow channels.

The parallel planes of the plates are oriented vertically, which is not the orientation most conducive for effective thermal conduction to the vertical sides of the module. When the flow channels are completely voided, conduction between the inner and outer plates can effectively occur only through the aluminum walls of the flow channels that enclose the helium tubes and the top and bottom module walls. This raises a concern about the capacity of the module to effectively conduct heat from the inner to outer plates, assuming the vertical sides of the module are adequately cooled by the cavity flood system. To address this concern, a three-dimensional transient thermal conduction model of the front row 1 module, using the HEATEL code, was developed. The boundary conditions and decay power distributions are symmetrical with respect to a vertical plane that bisects the central flow channels and helium tubes, so only half of the module was modeled (i.e., see the dashed rectangle show in Figure 2 and labeled model domain). The top, bottom, and symmetry plane boundaries are adiabatic, and the vertical sidewall is subjected to convection cooling by water at the local saturation temperature. The convective heat transfer coefficient is a free parameter in the model.

Under decay heat conditions the unique geometrical shapes of the solid structure become less important from a thermal perspective. Therefore, instead of modeling the complicated plate geometries of the module, a simplified Cartesian grid was used. A vertical slice through the 3-D grid is shown in Figure 3, while a 3-D perspective of the model grid is provided in Figure 4. The rectangular inclusions represent the flow channels: four in the exterior aluminum wall and the row of flow channels separating the interior and the peripheral lead plates. The right side of the grid is a plane of symmetry and therefore adiabatic. Because this surface is adiabatic, neglecting the additional surface area due to the semi-circular helium tube indentations is reasonable. The cross-sectional areas of the two lead plates are preserved. All of the heat transfer between the two plates is assumed to occur by thermal conduction through the narrow aluminum "bridges" that separate the flow channels. The lengths and widths of these "bridges" are preserved. Since the surfaces of the flow channels are assumed to be adiabatic, the flow channel geometries are not important. The top and bottom grid boundaries are adiabatic surfaces. The decoupler is below the module, and the row 2 module is above. The left side of the grid is the left vertical exterior surface of the module that is exposed to the cavity flood fluid. The cavity flood fluid, which is assumed to be at the local saturation temperature (i.e., typically on the order of $118^{\circ} \mathrm{C}$ ), convectively cools this surface. There is assumed to be a uniform one mil. air-filled gap between the lead and the aluminum.

In the HEATEL model, all of the decay power is assumed to be generated in the lead, and it varies both spatially and temporally. The power source terms are based on physics calculations for $1700 \mathrm{MeV}$ protons with a beam current of $100 \mathrm{~mA}$, [1]. The spatial power distribution varies in the beamwise direction and in the vertical direction. The decay curve is a function of elapsed time from beam shutdown. The steady-state operating power for half of the front horizontal row 1 module is $144.5 \mathrm{~kW}$. This power drops precipitously when beam shutdown occurs. Within ten seconds the power will have dropped below one percent of the steady-state value. The decay curve is shown in Figure 5. Figure 6 shows the axial (in the beamwise direction) relative power density distribution for the front top horizontal row 1 module. The axial distance is measured from the front of the module. The module power density is a minimum at the front of the module and a maximum at its rear. Figure 7 shows the vertical (axially averaged) relative power density variation 
for the lead in the top modules. The vertical dimension is measured from the bottom of the row 1 module, and the row 1 module spans the distance from 0.0 to $19.04 \mathrm{~cm}$. Note that the vertical ordinate of the plot is the natural logarithm of the power density. In HEATEL this curve is normalized to the mean power density, so it determines the vertical spatial distribution of the relative power density.

The convection heat transfer coefficient for the side of the module exposed to the cavity flood fluid was varied parametrically between the values for natural convection with single-phase water and for steam, 537.0 and $9.95 \mathrm{~W} / \mathrm{m}^{2} \mathrm{~K}$ respectively. The values of the coefficients were calculated from the Nusselt number correlation for natural convection from a vertical plate with the dimensions of the side of the row 1 module and with constant heat flux. Equation (1) is the correlation for the mean Nusselt number for laminar natural convection from a vertical plate of height $\mathrm{L}$ with constant wall heat flux, [2]:

$$
\mathrm{Nu}_{\mathrm{m}}=0.75\left(\mathrm{Gr}_{\mathrm{x}}^{*} \mathrm{Pr}\right)_{\mathrm{x}=\mathrm{L}}^{5} \text { for } 10^{5} \leq\left(\mathrm{Gr}_{\mathrm{x}}^{*} \mathrm{Pr}\right) \leq 10^{11}
$$

where

$$
\mathrm{Gr}_{\mathrm{x}}^{*} \equiv \mathrm{Gr}_{\mathrm{x}} \mathrm{Nu}_{\mathrm{x}}=\frac{g \beta \dot{q}_{w} \mathrm{x}^{4}}{\mathrm{k} v^{2}}
$$

nomenclature:

$\begin{array}{ll}\mathrm{g} & \text { gravitational acceleration } \\ \mathrm{Gr}_{\mathrm{x}}^{*} & \text { modified Grashoff number } \\ \mathrm{h} & \text { convection heat transfer coefficient } \\ \mathrm{k} & \text { thermal conductivity } \\ \mathrm{L} & \text { height of plate } \\ \mathrm{Nu}_{\mathrm{m}} & \text { mean Nusselt number } \\ \mathrm{Pr} & \text { Prandtl number } \\ \dot{\mathrm{q}}_{\mathrm{w}} & \text { wall heat flux } \\ \mathrm{x} & \text { vertical dimension } \\ \beta & \text { bulk coefficient of thermal expansion } \\ v & \text { kinematic viscosity }\end{array}$

The wall heat flux was assumed to be $3.88 \mathrm{~kW} / \mathrm{m}^{2}$, which is based on a decay power value of one percent of the steady-state power. Using water properties at $120^{\circ} \mathrm{C}$ [3], the heat transfer coefficient was calculated to be $536.8 \mathrm{~W} / \mathrm{m}^{2} \mathrm{~K}$, and using steam properties at $400 \mathrm{~K}$ [3], the heat transfer coefficient was calculated to be $9.95 \mathrm{~W} / \mathrm{m}^{2} \mathrm{~K}$. The coefficients for two-phased heat transfer will fall between these two limits. In reality, the module sidewalls will be subjected to mixed convection rather than pure natural convection, because of the thermosyphon circulation within the cavity vessel. This circulation is a function of both the total power dissipated by the cavity flood system and the flow passage geometry within the cavity vessel. The large scale circulation of the cavity flood fluid is a complex problem, and the flow passage design details are not currently specified. Therefore, the forced convection contribution to heat transfer on the sidewalls of the row 1 top horizontal module is neglected. This is a conservative omission since the forced convection component of mixed convection will only enhance the heat transfer coefficient. 


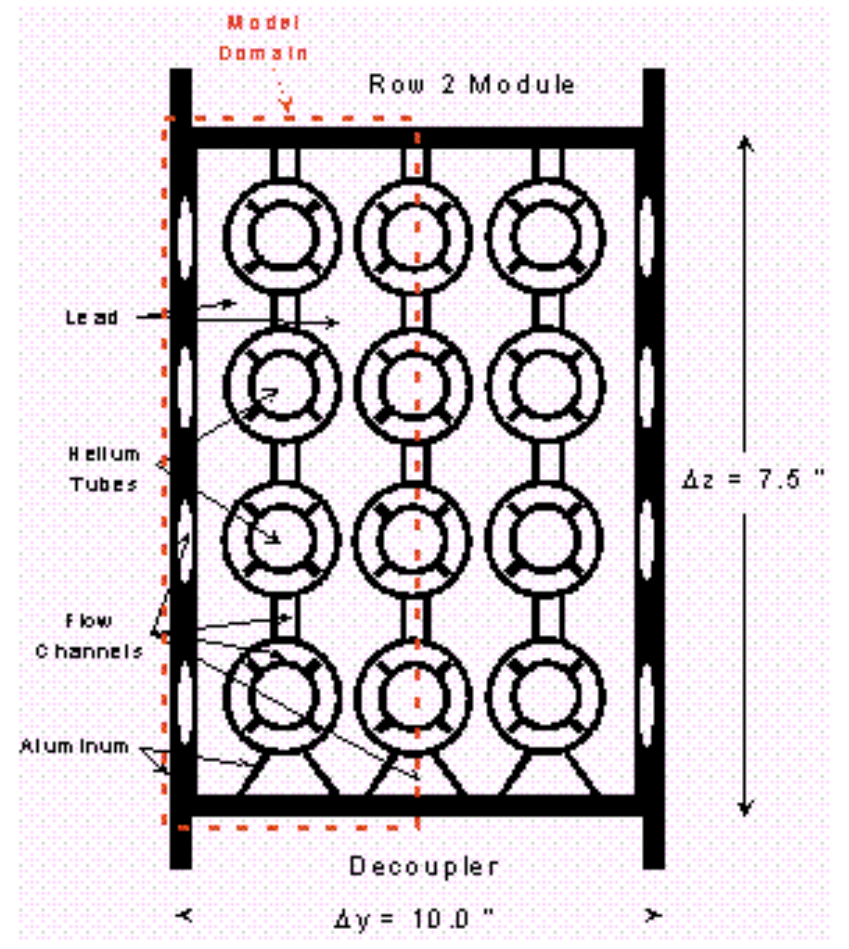

Figure 2. Cross-section of a top horizontal row 1 module showintg model domain.

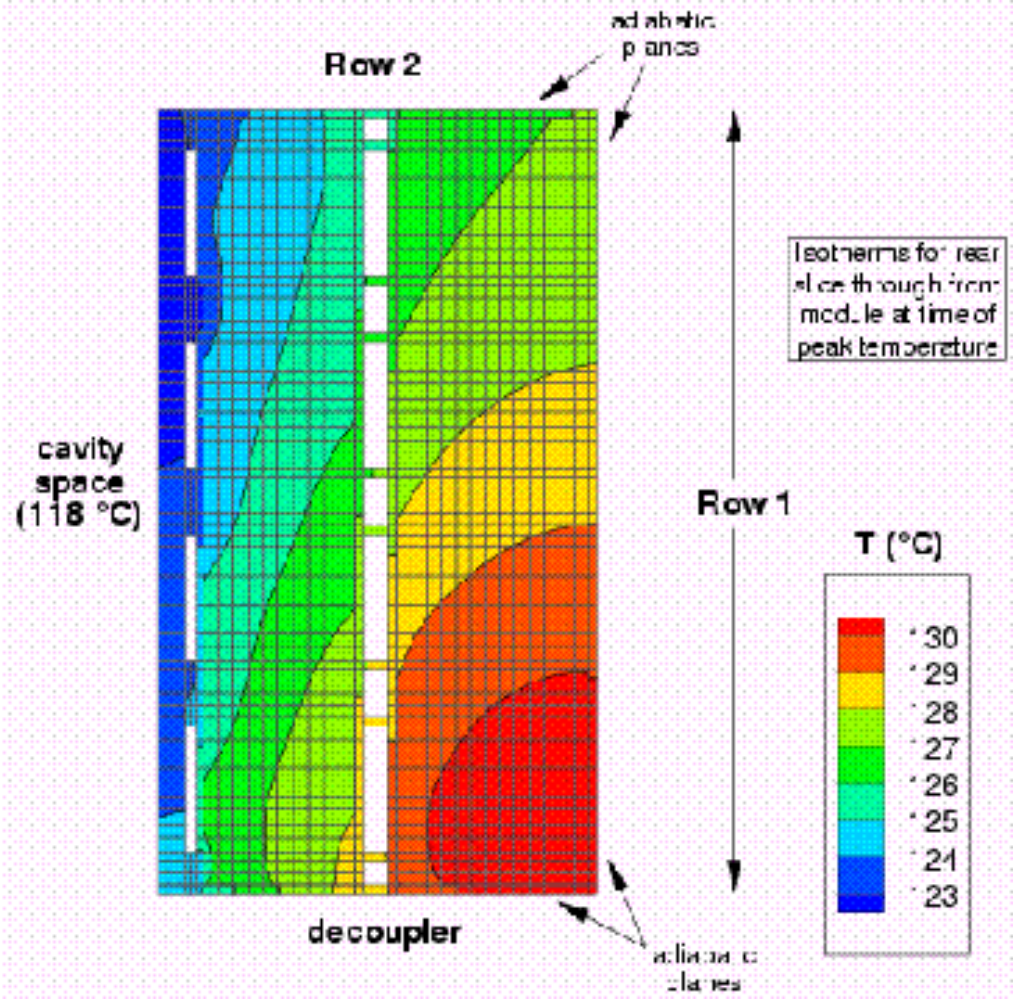

Figure 3. The HEATEL finite-element grid (vertical slice) of a top horizontal row 1 module. 


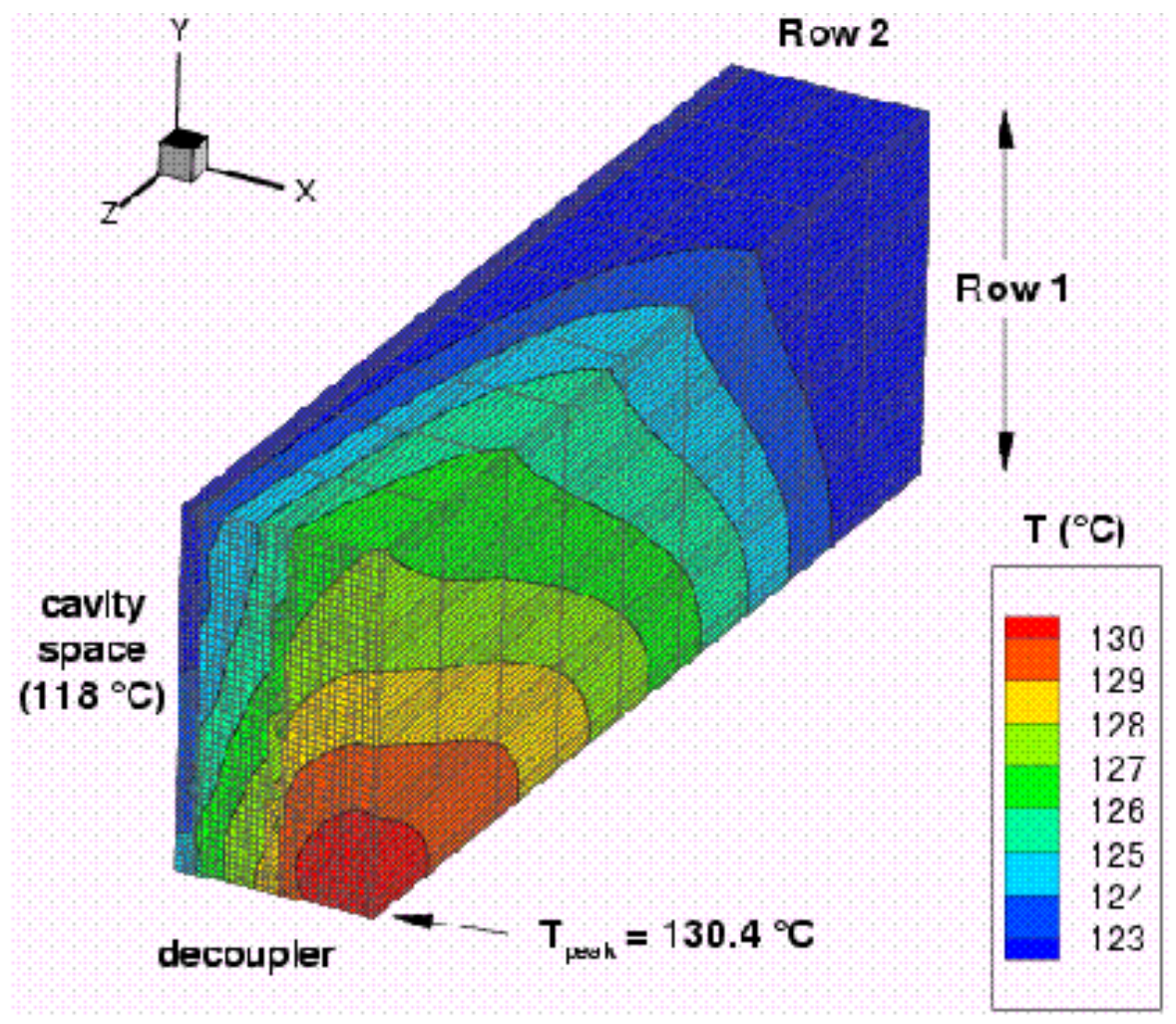

Figure 4. The HEATEL finite-element grid (3-D perspective) of a top horizontal row 1 module.

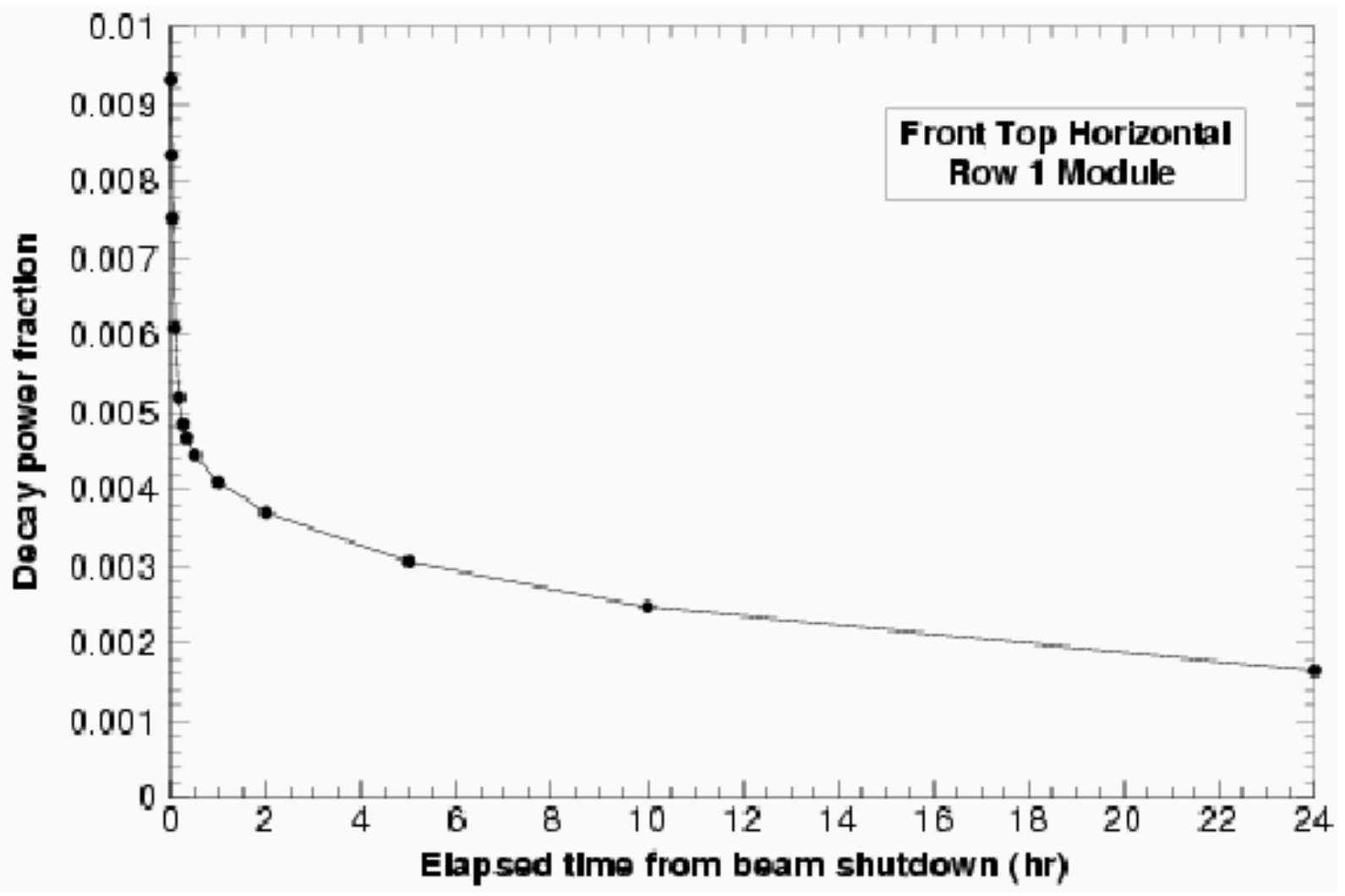

Figure 5. Decay power curve for the front top horizontal row 1 module. 


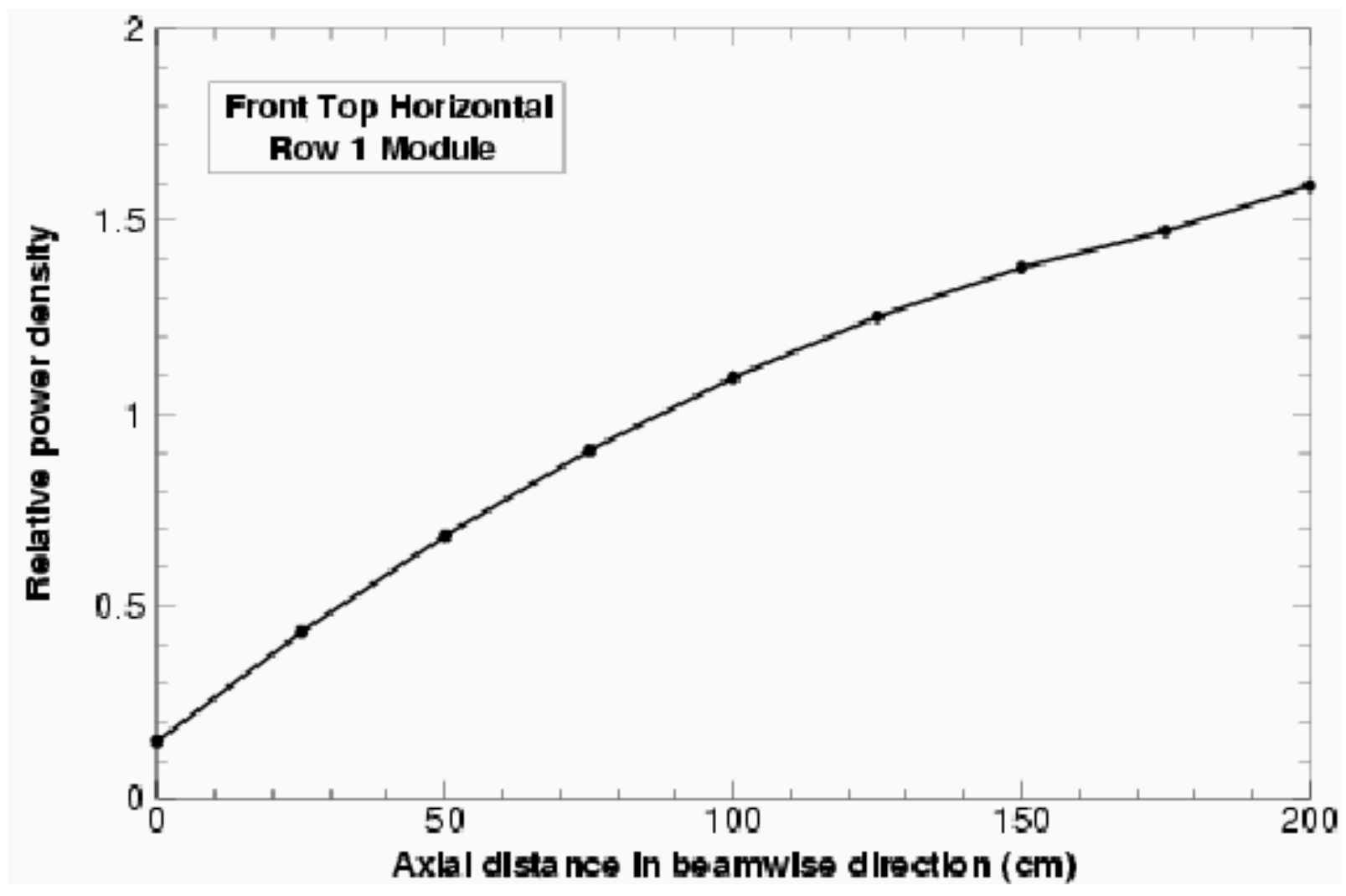

Figure 6. Axial relative power distribution for the front top horizontal row 1 module.

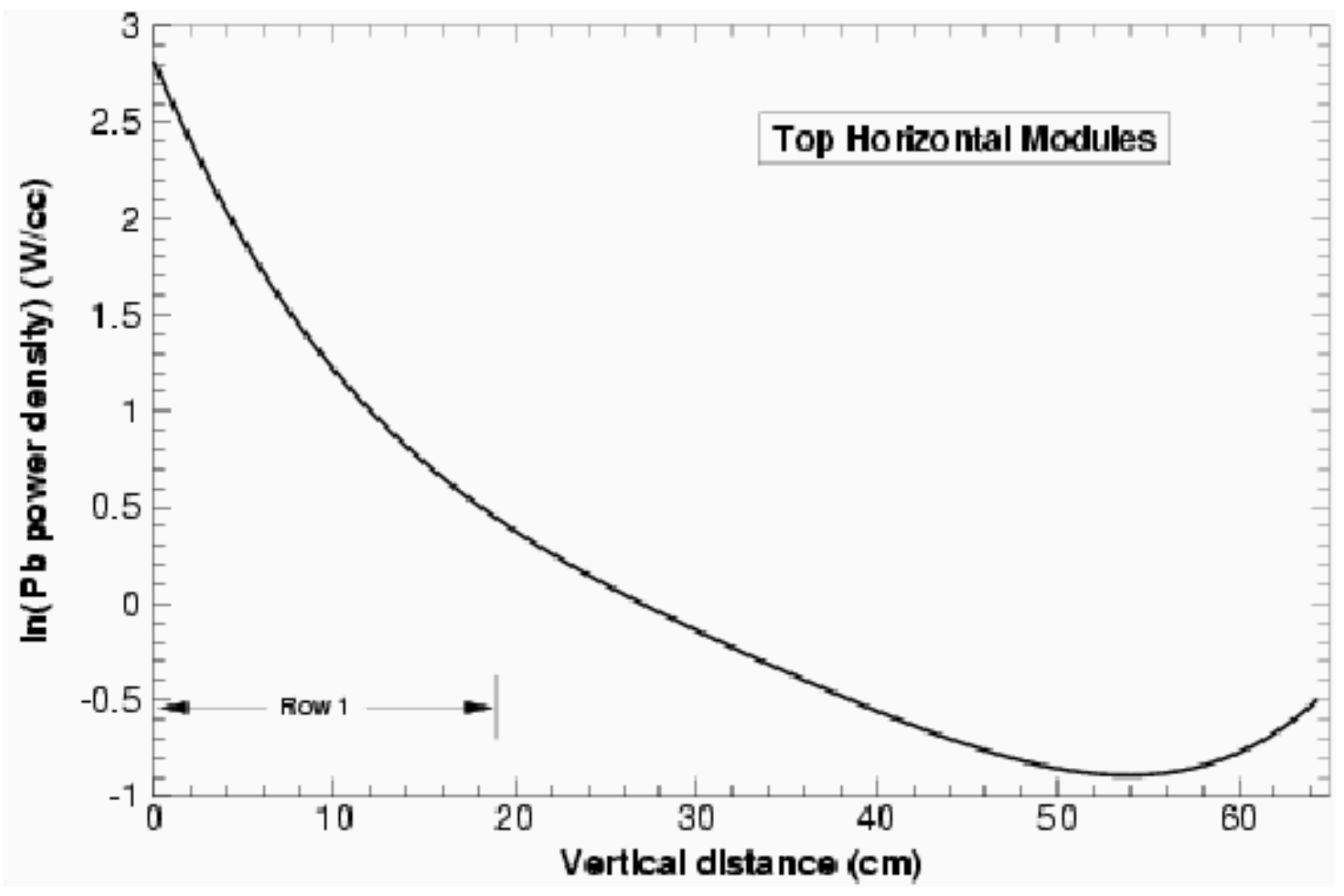


Figure 7. Vertical relative power distribution for the top horizontal modules.

\section{Thermal Conduction Model Results}

Figure 8 shows the transient peak lead and aluminum temperatures for the top front horizontal row 1 module when the CFS cools the module by single-phase natural convection of liquid on the vertical sidewalls (i.e., $\mathrm{h}=537 \mathrm{~W} / \mathrm{m}^{2} \mathrm{~K}$ ). Conservatively, the module is assumed to dryout at beam shutdown. The maximum peak metal temperatures occur thirty minutes after beam shutdown, and they are $130.4^{\circ} \mathrm{C}$ and $130.35^{\circ} \mathrm{C}$ for lead and aluminum, respectively. Hereafter, because of the negligible difference between the peak lead and aluminum temperatures, only the peak lead temperatures will be presented. Figure 9 shows the transient peak metal temperatures when dryout occurs at beam shutdown and the module is cooled by single-phase natural convection of stream, $\left(\mathrm{h}=9.95 \mathrm{~W} / \mathrm{m}^{2} \mathrm{~K}\right)$. The maximum peak metal temperature of $273.6^{\circ} \mathrm{C}$ occurs 8.7 hours after beam shutdown. Figure 10 shows the influence of the elapsed time between beam shutdown and dryout on the peak metal temperatures. Single-phase natural convection cooling with liquid is assumed. The peak temperature very quickly rises to a maximum and thereafter drops slowly as the deposited power decays. Irrespective of the dryout times, the module peak metal temperatures ultimately follow a single curve as they drop. This suggests that the conduction cooling of the module is a quasiequilibrium process.

Figure 11 shows the peak metal temperatures for six different values of the convection heat transfer coefficient that span the range between values for single-phase steam and water. The temperatures are shown as functions of the dryout time. It is evident that the relationship between the peak metal temperature and the value of the heat transfer coefficient is non-linear. Decreasing the heat transfer coefficient from 500 to $50 \mathrm{~W} / \mathrm{m}^{2} \mathrm{~K}$, increases the peak metal temperature by $35^{\circ} \mathrm{C}$ if module dryout is assumed to occur at beam shutdown and approximately $25^{\circ} \mathrm{C}$ if dryout is delayed $7.5 \mathrm{hrs}$. Decreasing the heat transfer coefficient from 50 to $10 \mathrm{~W} / \mathrm{m}^{2} \mathrm{~K}$, increases the peak metal temperature by $80^{\circ} \mathrm{C}$ if dryout occurs at $7.5 \mathrm{hrs}$. The convection heat transfer coefficient could be degraded by the presence of steam produced by boiling on the target ladders below. For this steam to be present, the cavity flood fluid adjacent to the top blanket modules must be at the local saturation temperature. Any significant decrease in the convection heat transfer coefficient due to two-phase flow effects will increase the wall temperature and trigger the onset of nucleate boiling (ONB). Boiling is a very efficient mechanism for removing heat from a surface, and it is characterized by effective heat transfer coefficients that are much larger than those for single-phase liquid convection heat transfer. A reasonable conclusion from these results is that as long as there is some cavity flood liquid available to wet the exterior walls of the top modules the cavity flood system will adequately cool these modules. 


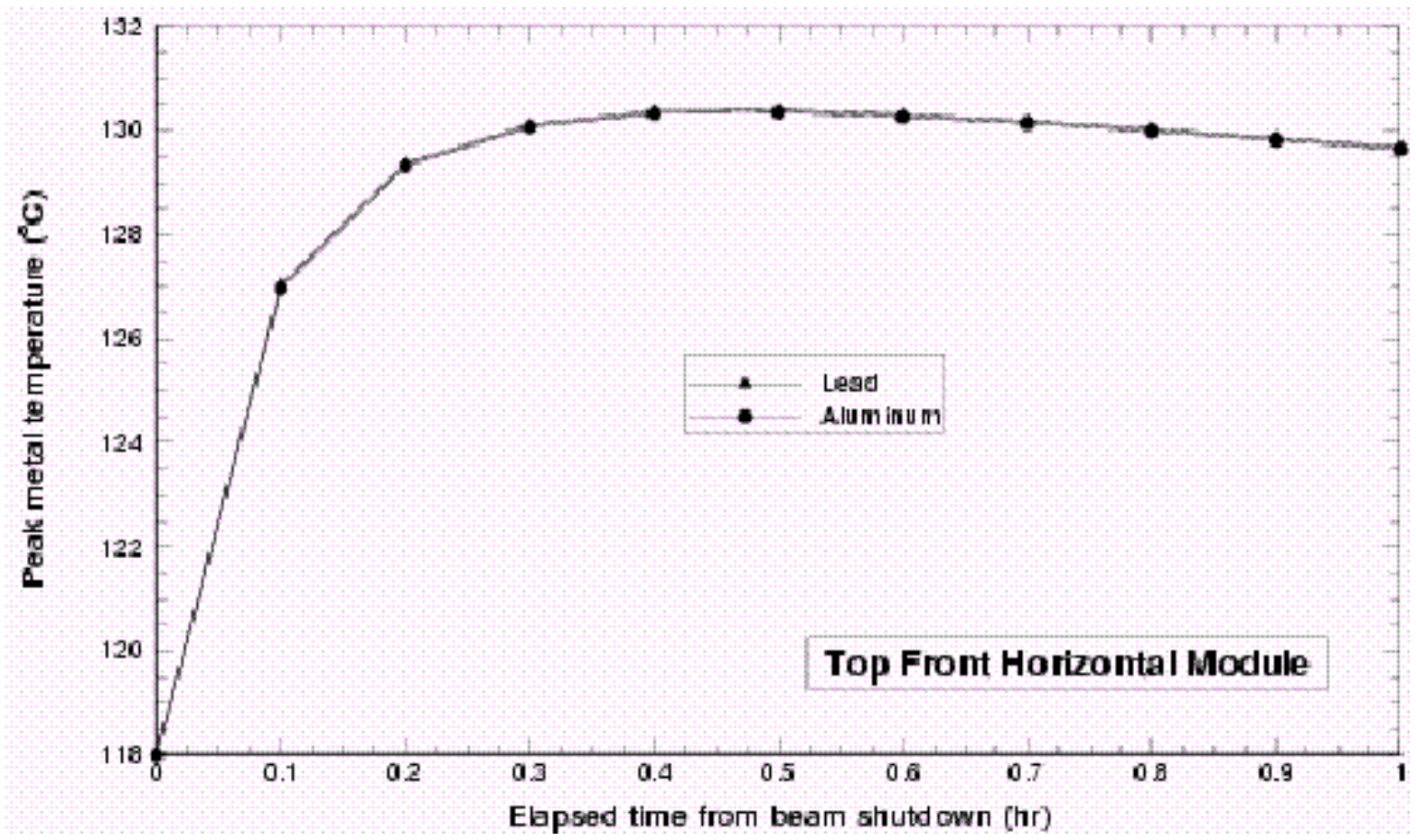

Figure 8. Peak metal temperatures with dryout occurring at beam shutdown and with single-phase liquid cavity flood cooling $\left(\mathrm{h}=537 \mathrm{~W} / \mathrm{m}^{2} \mathrm{~K}\right)$.

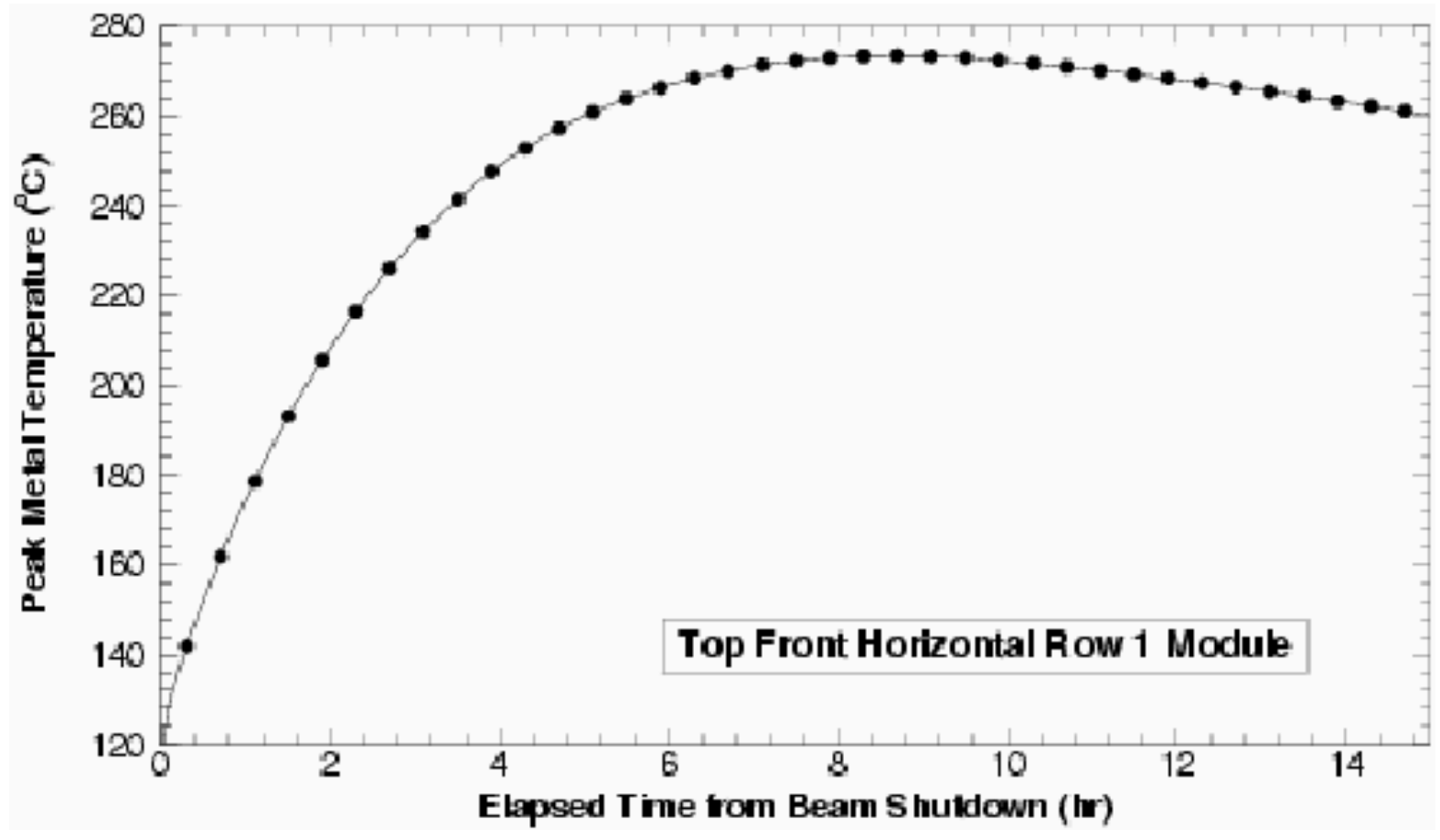

Figure 9. Peak metal temperatures with dryout occurring at beam shutdown and with single-phase steam cavity flood cooling $\left(\mathrm{h}=9.95 \mathrm{~W} / \mathrm{m}^{2} \mathrm{~K}\right)$. 


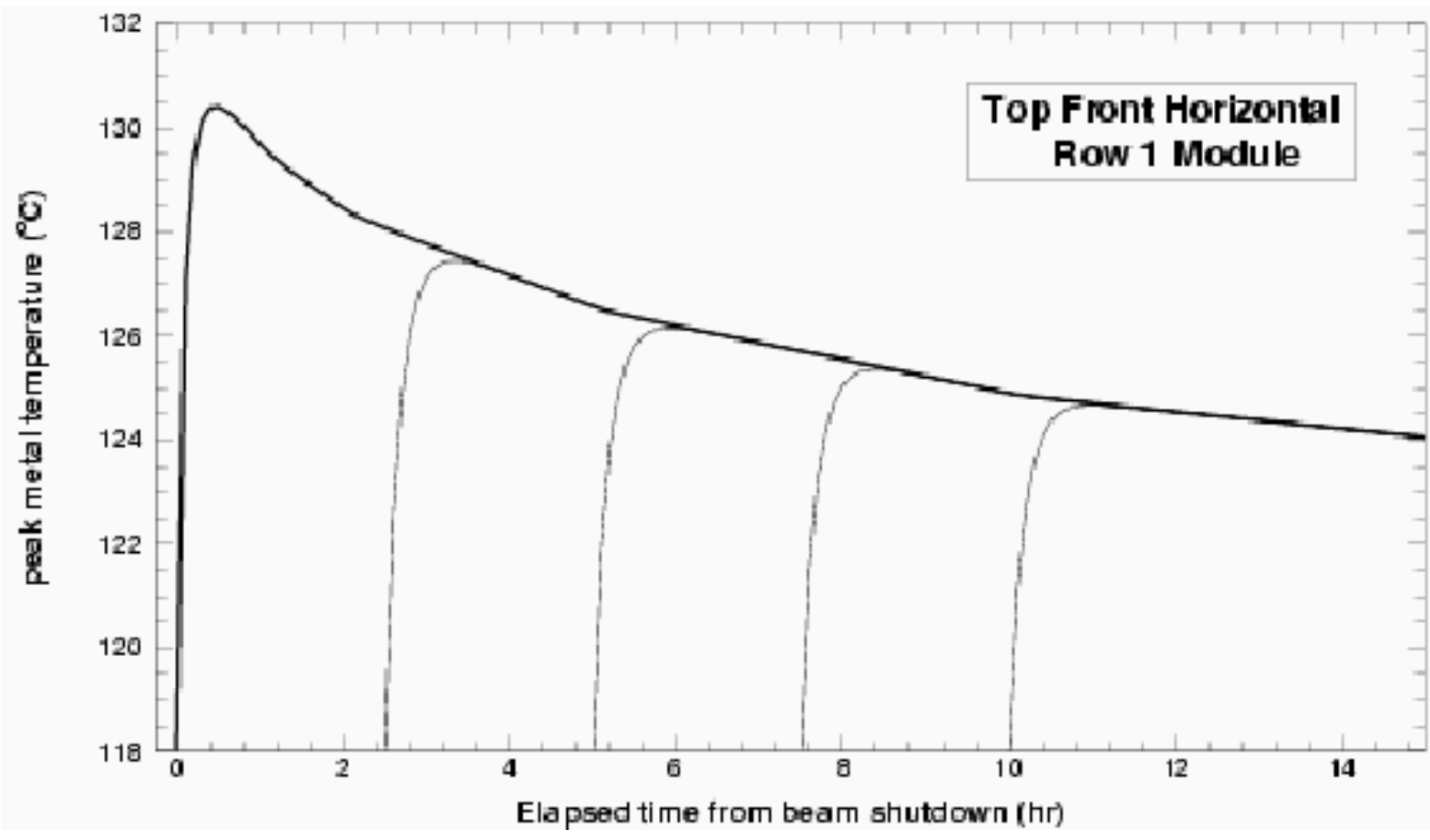

Figure 10. Peak metal temperatures for several dryout times and with single-phase liquid cavity flood cooling $\left(\mathrm{h}=537 \mathrm{~W} / \mathrm{m}^{2} \mathrm{~K}\right)$.

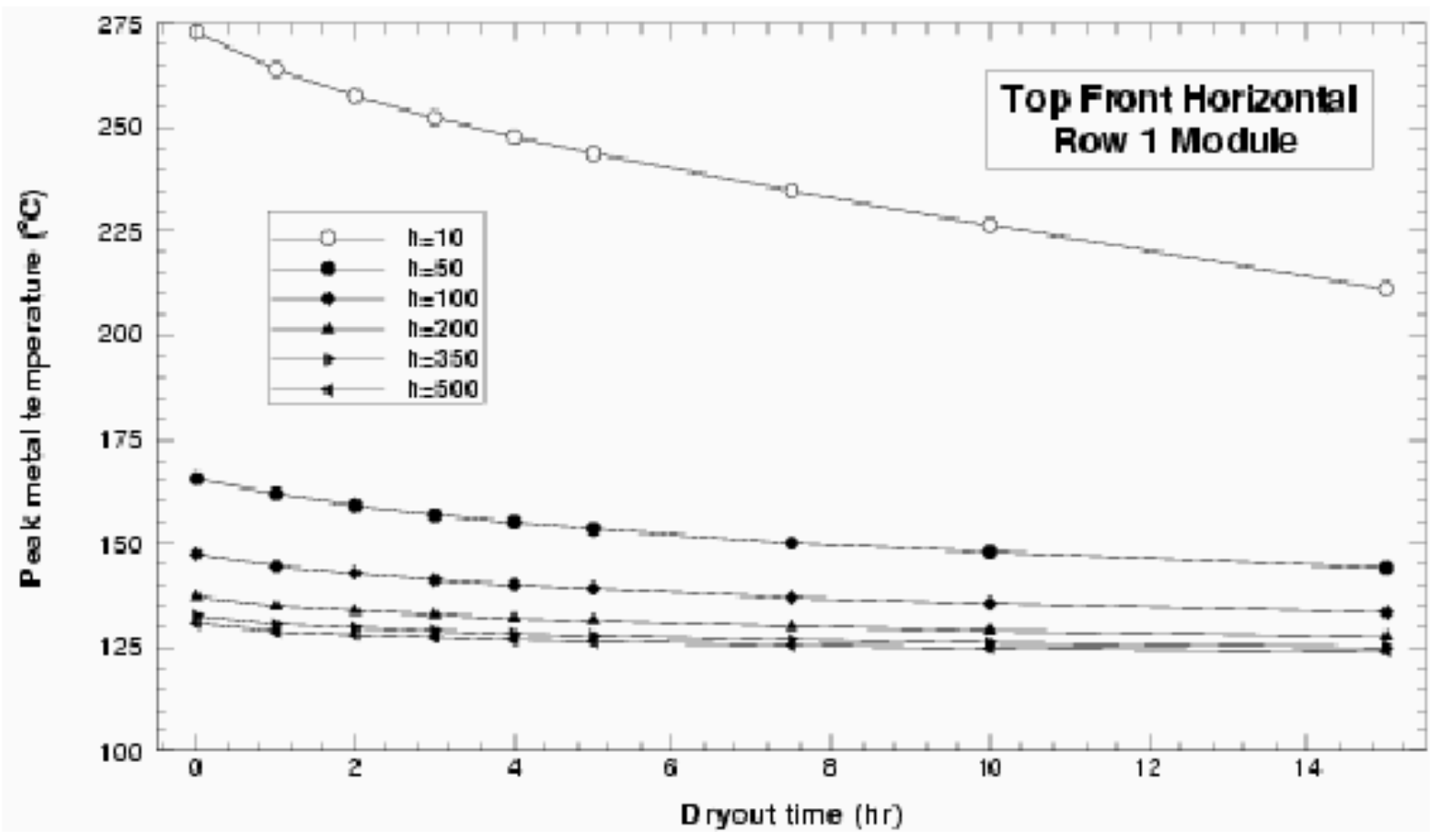

Figure 11. Peak metal temperatures for several values of the cavity flood heat transfer coefficient in the two-phase natural convection flow regime and dryout times in the range from 0.0 to 15.0 hours. 


\section{Top Shield Slots}

Steam produced by boiling of the cavity flood fluid when in contact with internally dry target rungs has the potential to collect in two upper regions of the cavity vessel. These two regions (i.e., one on each side of the beam centerline) are potential steam traps which are located beneath the vertical slots as shown in Figure 1 . The two regions are bounded on the sides by the top and lateral blanket modules, while they are bounded on the top by the top shield.

If sufficient amounts of steam collect in these regions to cover the sidewalls of the top horizontal modules, then the CFS will be unable to adequately cool these blanket modules. Vertical slots in the top shield, shown in Figure 1, are necessary to allow steam to pass through freely. The required slot widths are determined below using two different analysis approaches: (1) a simple scoping analysis; and (2) a twophase TRAC model.

The required slot width is a function of the steam production rate resulting from heat being dissipated from the internally dry target ladders. The target decay power information used to calculate the steam production rate is based on physics calculations after 274 days of operation of the accelerator with $1700 \mathrm{MeV}$ protons and a beam current of $100 \mathrm{~mA},[1]$. The highest power target ladder of the thirteen is number five, with a decay power at beam shutdown of $52.47 \mathrm{~kW}$. This power is conservatively applied to all of the ladders, thus removing the steam production gradient in the beam-wise direction from consideration. Half of the ladders are assumed to produce steam below the front set of top modules, and this steam is evenly split between the two sides of the module. The assumed decay power producing steam on one side of the front top modules is $170.53 \mathrm{~kW}$. At $27 \mathrm{psia}$, the heat of vaporization for water is $949.2 \mathrm{BTU} / \mathrm{lb}_{\mathrm{m}}$ or $2.206 \mathrm{MJ} / \mathrm{kg}$, [3]. If all of the target decay power is devoted to vaporization, the steam production rate is expressed by equation (3), the ratio of the decay power to the heat of vaporization.

$$
\dot{\mathrm{m}}_{\mathrm{stm}}=\frac{\dot{\mathrm{Q}}}{\mathrm{h}_{\mathrm{fg}}}
$$

The steam production rate for one side of the front set of top modules is $0.0773 \mathrm{~kg} / \mathrm{s}$.

\section{Analytical Approach}

As long as the two regions below the top shield and between the top/lateral modules have void fractions less than one, the CFS can adequately cool the internally dry top blanket modules. Figure 12 is a schematic of one of the slots that shows a scenario whereby steam can fill the regions adjacent to the top modules and prevent effective CFS cooling. For a given slot width, there is a steam flowrate through the slot with a pressure drop equal to the single-phase liquid hydrostatic pressure difference between the top and bottom of the top shield. If the steam flowrate is further increased, the free surface will back down into the region below the top shield until the hydrostatic pressure difference equals the irreversible pressure drop in the slot. The hydrostatic pressure difference between the top and bottom of the top shield is externally imposed by the cavity flood liquid because of other flow passages through and around the periphery of the top shield. There are also slots between the lateral blanket modules that allow for lateral communication between the various cavity flood filled regions in the blanket and insure that the pressure below the top shield will be close to hydrostatic.

The required slot width was determined using the 1-D mechanical energy balance: 


$$
\frac{P_{\text {bot }}}{\rho}+\frac{V_{\text {in }}^{2}}{2}+g z_{\text {bot }}=\frac{P_{\text {top }}}{\rho}+\frac{V^{2}}{2}+g z_{\text {top }}+\left(\sum \mathrm{K}+\frac{\mathrm{EL}}{D_{\mathrm{h}}}\right) \frac{\mathrm{V}^{2}}{2}
$$

This equation can be manipulated into a cubic equation for the slot width expressed as:

$$
\mathrm{D}^{3}+\mathrm{aD}+\mathrm{b}=0
$$

where:

$$
\mathrm{a}=\frac{\left(1+\sum \mathrm{K}\right) \dot{\mathrm{m}}_{\text {stm }}^{2}}{2 \rho \mathrm{W}^{2}(\Delta \mathrm{P}-\rho \mathrm{g} \Delta \mathrm{z})} \text { and } \mathrm{b}=\frac{\mathrm{el} \dot{\mathrm{m}}_{\text {stm }}^{2}}{4 \rho \mathrm{W}^{2}(\Delta \mathrm{P}-\rho \mathrm{g} \Delta z)}
$$

The pressure drop along the slot is the hydrostatic difference between the top and bottom of the top shield with water at $100^{\circ} \mathrm{C}$. The inlet velocity of the steam in the region below the top shield is ignored. The form loss coefficient for the sudden contraction at the slot entrance has a value of 0.42 and a loss of one velocity head is assumed at the exit.

The Blasius formula, given below, for smooth pipes was used to evaluate the friction factor:

$$
\mathrm{f}=0.316 \mathrm{Re}^{-1 / 4}
$$

The slot was assumed to have a length in the beamwise direction equal to that of the front set of top modules. The hydraulic diameter for this long narrow slot is approximately twice the slot width. Steam properties were assumed to be the mean of the entrance and exit saturation properties. With these assumptions, the values of the two coefficients "a" and "b" in Eq. (5) are $-5.46039 \times 10^{-8} \mathrm{~m}^{2}$ and -1.62715 $\mathrm{x} 10^{-9} \mathrm{~m}^{3}$, respectively. This equation can be solved either directly or iteratively, and there is one real root and two complex conjugates. The calculated slot width is $1.1917 \times 10^{-3} \mathrm{~m}$ or $0.0469 \mathrm{in}$. This is the threshold slot width for steam backing down into the two regions below the top shield. For wider slots, the specified bounding steam mass flowrate is insufficient to support flow with a void fraction of one and the imposed hydrostatic pressure drop. The steam velocity in the slot is $36.33 \mathrm{~m} / \mathrm{s}$ and the Mach number is 0.075 . The assumption of incompressible flow is justified.

\section{Numerical Approach}

A TRAC model of the two-phase flow through the top shield was developed to more rigorously determine required slot widths. The simple calculation described above does not account for the flashing that occurs as saturated liquid rises and the local saturation pressure drops. Conservatively assuming no net transfer between the CFS and the cavity pool, the cavity flood fluid within the vessel will circulate as a thermosyphon, with two-phase upflow in the central region of the cavity vessel, and single-phase downflow through the peripheral region. A realistic hydraulic model of this circulation pattern would require a complicated model; with heat transfer surfaces for boiling, and accurate geometric parameters, such as flow areas and hydraulic diameters, to determine the flowrate. The flow path geometries are not well defined. The objective of a model is to determine the threshold slot width at which the regions between the top horizontal modules and the lateral modules become completely voided. A simple once through TRAC model is sufficient for satisfying this limited objective and this was the chosen option. 
Figure 13 is a schematic of the TRAC model for two-phase flow through a top shield slot that shows the elevations of the TRAC component junctions. The break components at the top and bottom of the model provide pressure boundary conditions. The top pressure is assumed to be atmospheric, and it represents the pressure at the cavity flood free surface. The bottom pressure is the pressure at the horizontal mid-plane of the target ladders. This is the elevation at which the steam production is assumed to occur, and this pressure is an input parameter to the TRAC model. The target ladders are modeled with a "tee" component. The "fill" component on the side of the "tee" supplies slightly superheated steam (i.e., 5 to $10^{\circ} \mathrm{C}$ superheat) at a specified mass flowrate. The "pipe" component above the "tee" models the region below the top shield between the top and lateral modules, the slot through the top shield, and the region above the top shield. The incoming liquid through the "break" component at the bottom is assumed to be at saturated conditions.

The pressure in the vicinity of the target ladders is a function of the circulation flowrate and the irreversible losses in the down-flow portion of the loop and is unknown. The maximum possible value is the singlephase hydrostatic pressure. The ladder pressure and the slot width were varied parametrically in the TRAC model input, and the model predicts the flow regime below the slot. The steam injection mass flowrate from the fill component was $0.0773 \mathrm{~kg} / \mathrm{s}$. Three regimes occurred: (1) dispersed two-phase upflow; (2) stratified two-phase upflow; and (3) downflow. The downflow regime is physically unrealistic, and occurred when the specified bottom pressure was lower than that possible in the natural circulation loop. The results are shown in Figure 14. The horizontal ordinate is the slot width, and the vertical ordinate is the difference between the bottom and top "break" component pressures. The downflow region is labeled, "inaccessible boundary conditions for cavity space". For slot widths greater than 0.2 inches, the two-phase flow below the slot will not stratify. For slot widths between 0.05 and 0.2 inches, the flow will stratify with sufficiently low values for the bottom pressure, and for slot widths smaller than 0.05 inches the flow below the slot will stratify at the specified steam injection rate, irrespective of the bottom pressure. These results are consistent with those of the simple analytical calculation. As long as the two-phase flow below the slot is dispersed, the vertical sidewalls of the top modules will be wetted and provide adequate cooling by the cavity flood system.

The fact that upflow is predicted by the TRAC model for a given bottom pressure is necessary but insufficient to guarantee that the pressure is physically realizable. In reality pressures in natural circulation loops tend to differ only marginally from hydrostatic values. Flowrates are generally low and consequently so are irreversible pressure drops. The resultant model pressure drops, shown in Figure 14, are close to the hydrostatic driving force level, $98.0 \mathrm{kPa}$. This suggests that slot widths greater than 0.05 inches are sufficient to prevent drying out of the slots, though the results of this simple once through TRAC model support the conclusion that this is categorically demonstrated only for slots wider than 0.2 inches. 


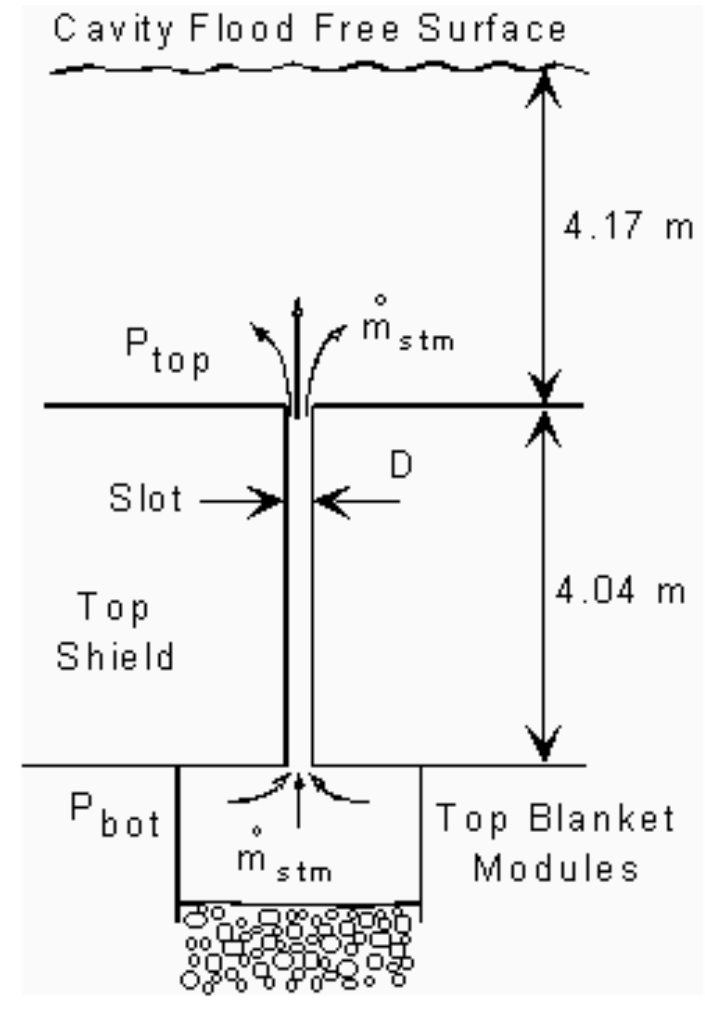

Figure 12. Schematic of a slot through the top shield.

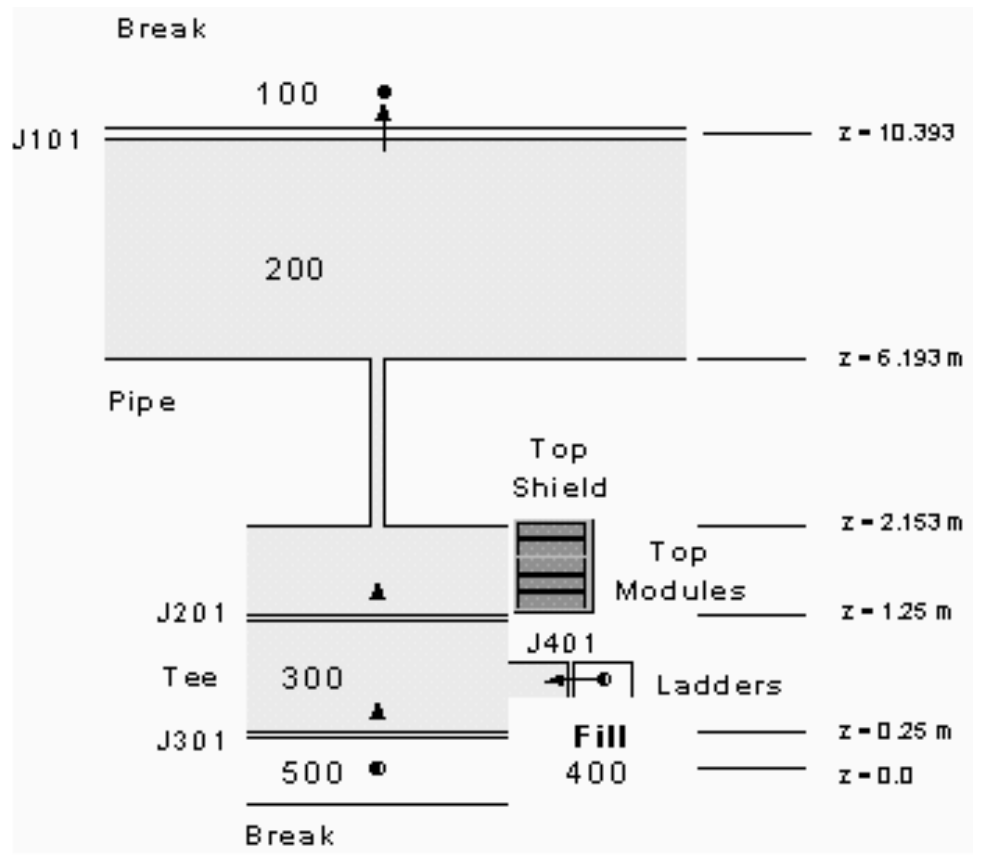

Figure 13. Schematic of the TRAC model that was utilized to determine the required width of the slot through the top shield. 


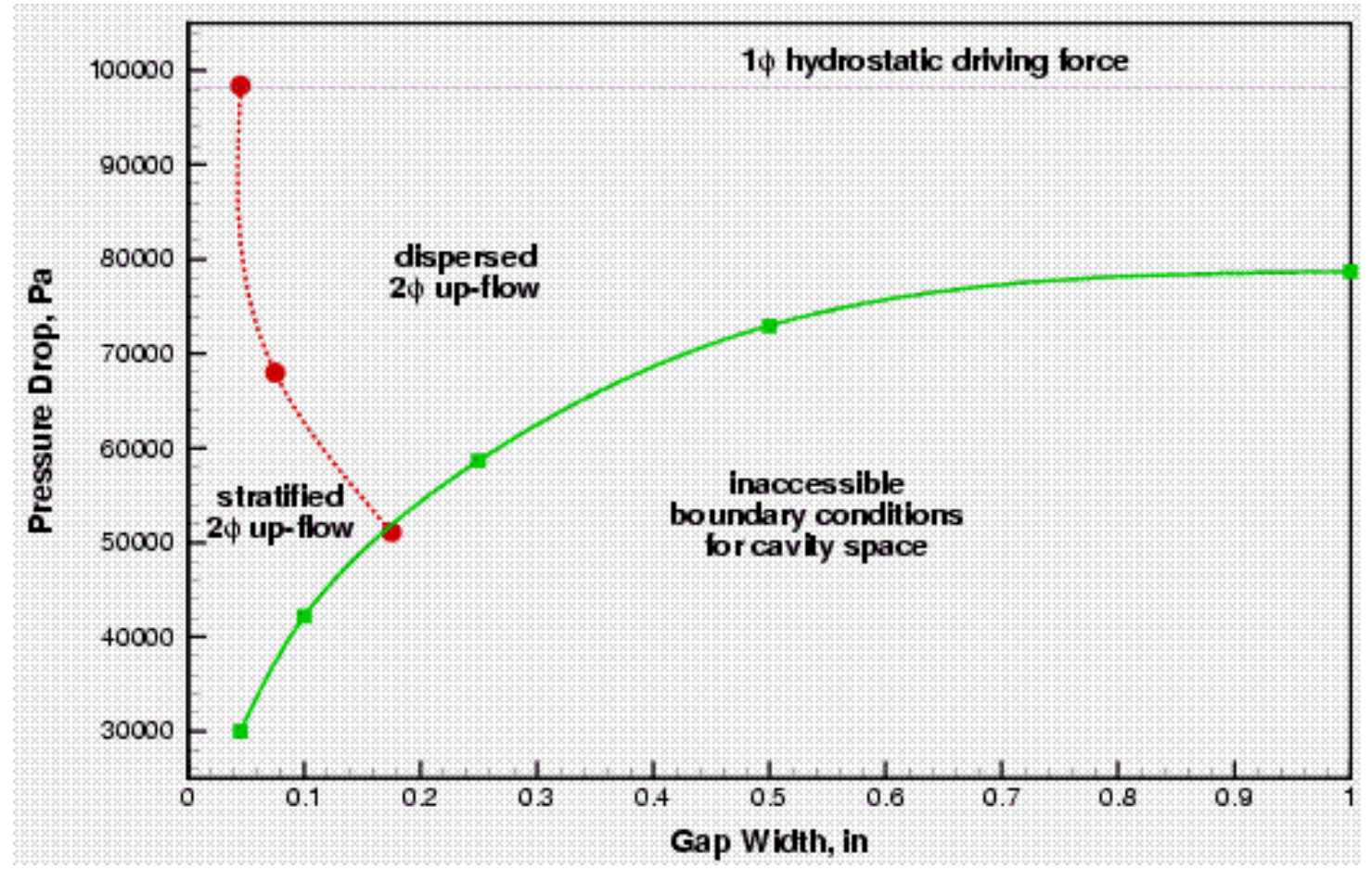

Figure 14. Flow regime plot for two-phase flow below the vertical slots in the top shield.

\section{Conclusions}

The concern that boiling on the external surfaces of the target ladders, when the cavity flood system has been activated, could prevent adequate cooling of the blanket modules above the target has been addressed. A transient thermal conduction model of the front top horizontal row 1 blanket module demonstrated that the cavity flood system will adequately cool the module when it is internally dry, as long as the vertical sides of the module are partially wetted. Slots through the top shield will prevent steam from collecting just below the top shield. The minimum slot width required, to insure that steam at the maximum production rate can pass freely through the top shield, is approximately 0.2 inches. This is certainly not restrictive since a slot width of approximately one half to one inch is realistic. Such a slot would not impede the upward flow of steam through the top shield and would insure that the two-phase flow below would be in a dispersed flow regime.

\section{References}

1. R. Kapernick, EXCEL Spread Sheet received from Los Alamos National Laboratory, December 1998.

2. Ozisik, M. N., "Heat Transfer a Basic Approach", McGraw-Hill Inc., 1985.

3. "1967 ASME Steam Tables" 